\title{
Gestão das políticas de atendimento aos alunos com necessidades educacionais especiais em municípios paulistas ${ }^{1}$
}

\author{
Management policies to serve students with special \\ educational needs in municipalities of São Paulo state
}

\author{
Juca Gil 2 \\ Rosângela Gavioli Prieto \\ Ana Paula de Oliveira Moraes Soto ${ }^{3}$ \\ Ana Paula Ribeiro Freitas ${ }^{5}$ \\ Ananda Grinkraut ${ }^{4}$ \\ Andrea de Carvalho Zichia ${ }^{5}$ \\ Luciane Muniz Ribeiro Barbosa ${ }^{6}$ \\ Paula Regina Cursino ${ }^{7}$ \\ Roseli Kubo Gonzalez ${ }^{6}$
}

\begin{abstract}
Resumo
O presente artigo tem como objeto a gestão das políticas de atendimento aos alunos com deficiência, transtornos globais do desenvolvimento e altas habilidades / superdotação. São apresentados alguns dos referenciais teóricos concernentes às temáticas relacionadas à gestão de políticas públicas, ao financiamento da educação e à educação especial que possibilitam uma aproximação da realidade. Discorre-se ainda sobre alguns resultados de pesquisa realizada sobre o tema e destaca-se que abordar arranjos institucionais públicos municipais da educação especial, focalizando gestão e financiamento, caracterizase como aspecto original desta investigação.
\end{abstract}

Palavras-chave: Educação especial; Gestão pública; Financiamento.

\begin{abstract}
This article has as its object the management of policies to serve students with disabilities, pervasive developmental disorders and high abilities / highly gifted. Are presented some of the theoretical frameworks concerning the subjects relating to the management of public policies, the education funding and the special education that enable an approximation of reality. The analysis considers still on some results of research on the theme and highlights that studying municipal institutional arrangements and funding for special education is characterized as a unique aspect of this research.

Keywords: Special education; Management of public policies; Education funding.
\end{abstract}

1 Componente de pesquisa mais ampla financiada pelo Conselho Nacional de Desenvolvimento Científico e Tecnológico (CNPq), realizada junto à Faculdade de Educação da Universidade de São Paulo (FEUSP).

2 Docentes UFRGS e Feusp - contatos, respectivamente, jucagil@uol.com.br e rosangel@usp.br.

3 Mestranda / Feusp.

4 Mestranda / FE Unicamp.

5 Mestre / Feusp.

6 Doutorandas / Feusp.

7 Pedagoga / UMC. 


\section{Introdução}

A literatura no campo da educação especial tem se voltado à divulgação de conhecimentos que apontam para vários aspectos, desde a defesa do direito de pessoas com deficiência, transtornos globais do desenvolvimento e altas habilidades / superdotação (BRASIL, 2008) à escolarização e às demais garantias expressas nos documentos legais, incluindo alguns poucos estudos de caráter mais descritivo sobre implantação de políticas públicas de atendimento, bem como de averiguação de práticas pedagógicas que sustentam seu atendimento com qualidade em serviços exclusivos de educação especial ou em classes comuns, com ou sem apoio especializado. Todavia, ainda pouco se tem divulgado sobre a gestão da educação especial como política pública em municípios e é particularmente exíguo o conhecimento sobre as formas de financiamento público adotadas para garantir o atendimento supostamente especializado.

No momento da elaboração do projeto de pesquisa, detectou-se que as pesquisas sobre educação especial nos municípios paulistas localizadas até aquele período apresentavam resgates históricos, análise de sua estrutura de atendimento e da coerência entre seus princípios e objetivos (PRIETO, 2000; SOUSA; PRIETO, 2001; DUARTE, 2004; PRIETO et al., 2006) e ainda avaliavam alguns impactos das ações implantadas (PRIETO; SOUSA, 2006; PRIETO, 2007)9. Outros estudos consultados reforçavam tendência à divulgação de descrições sobre a estrutura e organização da educação especial em municípios brasileiros ou se aproximavam aos comumente denominados relatos de experiências. Um destes relatos referia-se a um projeto de intervenção no município Paraguaçu Paulista com o objetivo de

8 Neste artigo também será utilizada a expressão necessidades educacionais especiais como uma categoria que abrange estes três segmentos.

9 Com exceção do estudo de Duarte (2004) sobre o município paulista de Mauá, as outras publicações divulgam resultados de pesquisa no município de São Paulo. mudar "a situação de precariedade do ensino especial oferecido aos alunos deficientes, assim como toda a estrutura de educação especial existente no município" (OLIVEIRA; POKER, 2002, p. 233); o estudo de Alpino e Emmel (2003) foi desenvolvido no ensino público regular de Londrina objetivando, entre outros aspectos, "investigar a existência das condições e apoios necessários" (p. 100) aos alunos com deficiência física, priorizando etapas da educação básica em municípios brasileiros; o estudo de Lauro et al. (2003) relatava resultado de projeto de intervenção na educação infantil, priorizando a formação em serviço de profissionais em Juiz de Fora MG, na perspectiva da educação inclusiva; o estudo de Silveira et al. (2003) buscou "levantar o número de crianças com necessidades educacionais especiais inseridas em creches da rede municipal de São Carlos, segundo a perspectiva de diretoras e educadoras" ( $p$. 122). Além destes estudos, outros versavam sobre política de educação especial em estados brasileiros. Matos (2007) realizou estudo com o objetivo de avaliar "a política de educação, no Estado de Sergipe, destinadas às pessoas com deficiência, no período de 1979 a 2001" (p. 77); Carvalho (2003) explorou a "política estadual de educação especial no atual quadro educacional maranhense e brasileiro" (p. 13); e Zanata (2003) focalizou, na rede estadual de ensino de São Paulo, particularmente, a "implantação de projeto de inclusão em uma escola de ensino fundamental" (p. 89).

Após a aprovação do projeto foram localizadas duas produções que abordam a temática do financiamento na educação especial: um artigo de Bassi e Viegas (2009), que "examina a Educação Especial entre 1998 e 2006, e procura demonstrar que o desempenho das suas matrículas, seja no setor público seja no setor privado foi fortemente influenciado pelo financiamento da educação" (p. 54); e um trabalho de Viegas (2009), que "apresenta uma revisão bibliográfica inicial no que tange à temática financiamento da educação e estudos preliminares sobre o financiamento da Educação Especial" (p. 1). 
Embora os referidos estudos sejam de fundamental importância para a área, ainda é preciso questionar: como os municípios brasileiros vêm estruturando as políticas de educação especial? Os planos e programas de atendimento escolar nos municípios priorizam o acesso e a permanência desse alunado na classe comum? Estão sendo garantidos serviços de apoio pedagógico especializado integrado à classe comum para viabilizar sua permanência na escola e condições que Ihes permitam apropriarem-se de conhecimentos? Que tipos de apoio educacionais especializados são oferecidos?

Em busca das respostas a essas questões, a pesquisa aqui relatada pretende organizar informações sobre a organização da educação especial em alguns municípios paulistas tendo como objetivos descrever e analisar a gestão das políticas de atendimento aos alunos com necessidades educacionais especiais, focalizando os arranjos institucionais que os municípios selecionados construíram para garantir o atendimento especializado desta população.

Para tanto, as abordagens qualitativa e quantitativa foram adotadas, pois conhecer a realidade educacional e, mais pontualmente sua política, requer agregar dados que forneçam pistas sobre os contextos histórico, social, cultural, político e econômico. Isto significa que também serão utilizadas fontes quantitativas, como forma relevante de obter informações que dêem conta da análise da política de educação especial em municípios paulistas, especialmente no tocante ao seu financiamento.

Nessa direção, o presente artigo apresentará breve contextualização da problemática anunciada para posteriormente descrever a pesquisa e parte dos resultados alcançados com a sua realização.

\section{Contextualizando a educação especial}

No Brasil, ações em favor da igualdade de direitos aos alunos com necessidades educacionais especiais ${ }^{10}$ vêm se concretizando há anos e têm, historicamente, sido influenciadas pelos movimentos internacionais direta ou indiretamente voltados às pessoas com deficiência. Tais ações estão assentadas no movimento pela inclusão social e escolar, atreladas "à construção de uma sociedade democrática, na qual todos conquistam sua cidadania e na qual a diversidade é respeitada e há aceitação e reconhecimento político das diferenças" (MENDES, 2002, p. 61). Seus desdobramentos no campo escolar implicam, ao menos, em assegurar a educação para todos, com garantia de matrícula na classe comum em escola mais próxima da residência do aluno, flexibilização curricular, acessibilidade física, de comunicação e sinalização, além de formação inicial e continuada de professores e as formas de atendimento educacional especializado que respondam as suas necessidades específicas.

No âmbito da legislação educacional brasileira, destaque deve ser conferido à Constituição Federal de 1988 (CF/88) que prevê o "atendimento educacional especializado aos portadores de deficiência, preferencialmente na rede regular de ensino" (arts. 206 e 208, respectivamente), como meio de efetivar a educação como "direito de todos". Após reiteração deste princípio na Lei de Diretrizes e Bases da Educação Nacional - Lei

10 Como explicitado anteriormente, essa terminologia é adotada para identificar alunos com deficiência, altas habilidades / superdotação e transtornos globais do desenvolvimento (TGD) que apresentam, no âmbito escolar, necessidades educacionais que exigem atendimento educacional especializado. Essas categorias coincidem com as divulgadas no documento "Política Nacional de Educação Especial na perspectiva da educação inclusiva"' (BRASIL, 2008), que define como "pessoa com deficiência aquela que tem impedimentos de longo prazo, de natureza física, mental ou sensorial que, em interação com diversas barreiras, podem ter restringida sua participação plena e efetiva na escola e na sociedade. Os alunos com transtornos globais do desenvolvimento são aqueles que apresentam alterações qualitativas das interações sociais recíprocas e na comunicação, um repertório de interesses e atividades restrito, estereotipado e repetitivo. Incluem-se nesse grupo alunos com autismo, síndromes do espectro do autismo e psicose infantil. Alunos com altas habilidades / superdotação demonstram potencial elevado em qualquer uma das seguintes áreas, isoladas ou combinadas: intelectual, acadêmica, liderança, psicomotricidade e artes, além de apresentar grande criatividade, envolvimento na aprendizagem e realização de tarefas em áreas de seu interesse" (BRASIL, 2008, p. 15). 
n. 9394 de 1996 (LDB/96) (art. 58), localiza-se na Resolução CNE/CEB n. 2 de 2001 a supressão dessa condição preferencial pela garantia de que a escolarização dessa população "deve ser realizada em classes comuns de ensino regular, em qualquer etapa ou modalidade da Educação Básica" (art. $7^{\circ}$ ), com a possibilidade de recorrerem ao atendimento de serviços de apoio especializado e, em caráter extraordinário e transitório, de serviços especializados (classes e escolas especiais, como exemplos) (arts. $9^{\circ}$ e 10).

Atualmente, a orientação nacional para o atendimento educacional especializado presente no documento Política Nacional de Educação Especial na perspectiva da educação inclusiva (PNEE/2008) suprime a possibilidade de caráter substitutivo da educação especial, além de definir que "o atendimento educacional especializado tem como função identificar, elaborar e organizar recursos pedagógicos e de acessibilidade que eliminem as barreiras para a plena participação dos alunos, considerando suas necessidades específicas" (BRASIL, 2008, p. 15). Assim,

As atividades desenvolvidas no atendimento educacional especializado diferenciam-se daquelas realizadas na sala de aula comum, não sendo substitutivas à escolarização. Esse atendimento complementa e/ou suplementa a formação dos alunos com vistas à autonomia e independência na escola e fora dela. (BRASIL, 2008, p. 15).

Destaca-se que a tarefa de organizar programas de atendimento educacional especializado a esse alunado é incumbência das esferas administrativas federal, estaduais e municipais. Todavia, a responsabilidade dos municípios brasileiros é muito superior, pois a partir da LDB/96 os seus encargos passaram a ser de oferecer educação infantil e "com prioridade, o ensino fundamental" (BRASIL, 1996a, art. 11). Tanto que os dados do Instituto de Estudos e Pesquisas Educacionais Anísio Teixeira (Inep) revelam que houve crescimento de 56\% no total das matrículas entre 2002 (448.601) e 2006 (700.624) e que o percentual de municípios brasileiros com matrículas na educação especial era de $65 \%$ naquele primeiro ano e atingiu $89 \%$ em 2006 (BRASIL, 2007).

Em 2006, das 700.624 matrículas em instituições públicas e privadas, 579.143 , ou seja, $82,66 \%$ eram referentes a vagas preenchidas nas primeiras etapas da educação básica, estando distribuídas conforme a tabela a seguir:

\section{Tabela - Número de matrículas em educação especial por etapa de ensino - 2006}

\begin{tabular}{|c|c|c|c|c|c|}
\hline \multirow{2}{*}{$\begin{array}{c}\text { Nível de } \\
\text { ensino }\end{array}$} & \multicolumn{5}{|c|}{ Matrículas } \\
\cline { 2 - 7 } & Total & $\begin{array}{c}\text { Escolas } \\
\text { e classes } \\
\text { especiais }\end{array}$ & $\%$ & $\begin{array}{c}\text { Escolas } \\
\text { e } \\
\text { classes } \\
\text { comuns }\end{array}$ & $\%$ \\
\hline Creche & 34.124 & 30.279 & 88,7 & 3.845 & 11,3 \\
\hline Pré-escola & 78.864 & 57.804 & 73,3 & 21.060 & 26,7 \\
\hline $\begin{array}{c}\text { Ensino } \\
\text { Fundamental }\end{array}$ & 466.155 & 199.691 & 42,8 & 266.464 & 57,2 \\
\hline Total & 579.143 & 287.774 & - & 291.369 & - \\
\hline
\end{tabular}

Fonte dos dados: BRASIL. MEC/INEP. Sinopse Estatística da Educação Básica: Censo Escolar 2006. Brasília: MEC/INEP, 2007.

Esses dados revelam que apenas no ensino fundamental havia prevalência de matrículas em classes comuns de escolas regulares; nas creches e pré-escolas os alunos com necessidades educacionais especiais eram atendidos em número significativamente maior em escolas e classes especiais.

Destaca-se que o aumento de matrículas de alunos com necessidades educacionais especiais nas classes comuns é, inegavelmente, uma fase imprescindível para garantir igualdade de direito à educação para essa população. Todavia, é preciso investir política e financeiramente para atender demandas específicas de alguns alunos, particularmente aqueles que apresentam necessidades educacionais especiais em decorrência de deficiência, transtornos globais do desenvolvimento e altas habilidades/ superdotação. A igualdade de direitos neste caso é preservada se combinada com o direito à diferença, que pode ser concretizado também pela disponibilização de um conjunto de provisões (serviços, equipamentos, materiais, profissionaiscapacitadoseespecializados para seu atendimento, entre outros) caracterizado por atendimento educacional especializado.

\section{Financiamento da educação especial}

Em consulta bibliográfica realizada sobre financiamento da educação especial, foi 
localizada uma publicação da Secretaria de Educação Especial (Seesp) do MEC, de 1996, como parte da denominada Série Institucional, intitulada Educação Especial no Brasil: perfil do financiamento e das despesas, de autoria de Candido Alberto Gomes e José Amaral Sobrinho, em cujas conclusões se encontram:

Os dados aqui reunidos mostram que a Educação Especial não é especial só no nome. Trata-se de um setor atípico que, no entanto, padece de pelo menos um problema típico da Educação como um todo no Brasil: a falta de dados para a gestão [...]. Faltam números e até noções gerais de despesas, custos, benefícios, efetividades, etc. Os poucos dados existentes são falhos, não revelando o que efetivamente é despendido em Educação Especial e em outros programas orçamentários. (BRASIL, 1996c, p. 111 e 113).

Embora a sustentação teórica seja quase inexpressiva, é comum nos depararmos com a defesa de hipóteses que pressupõem os custos da educação especial como sendo substancialmente mais altos do que os do ensino comum. Estas hipóteses fundamentam-se, muitas vezes, em dados informalmente cedidos por sistemas de ensino e impressões advindas do senso comum que associam o aumento de custos à qualidade de ensino, às diferenciações de insumos utilizados e às formas de atendimento diferenciadas, por serem classificadas como especializadas.

Do ponto de vista da legislação brasileira, inicialmente transparece a afirmação de que o dever do Estado para com a educação será efetivado mediante a garantia de "padrões mínimos de qualidade de ensino, definidos como a variedade e quantidade mínimas, por aluno, de insumos indispensáveis ao desenvolvimento do processo de ensino-aprendizagem", em destaque na LDB/96 (BRASIL, 1996a, art. 4', IX, grifo nosso). A vinculação entre custo e qualidade é abordada de forma mais explícita e contundente nos artigos 74 e 75 desta mesma Lei:

Art. 74 - A União, em colaboração com os Estados, 0 Distrito Federal e os Municípios, estabelecerá padrão mínimo de oportunidades educacionais para 0 ensino fundamental, baseado no cálculo do custo mínimo por aluno, capaz de assegurar ensino de qualidade [...].

Art. 75 - A ação supletiva e redistributiva da União e dos Estados será exercida de modo a corrigir, progressivamente, as disparidades de acesso e garantir o padrão mínimo de qualidade de ensino. (BRASIL, 1996, grifo nosso).

Poucos dias depois de entrar em vigor a LDB/96, também foi promulgada a Lei 9.424/96, que regulamentou a Emenda Constitucional $n^{\circ}$. 14, criando o Fundo de Manutenção e Desenvolvimento do Ensino Fundamental e de Valorização do Magistério (Fundef). A concomitância temporal tem sua correspondente consonância política, sendo visível que estes dois documentos legais visam a implementar parte das questões anunciadas pela LDB/96 nos trechos citados anteriormente.

A mesma lei, em seu artigo 13, determina o que poderíamos considerar como sendo seis critérios para mensurar a qualidade do ensino e determinar o custo-aluno em caráter nacional:

[...] I - estabelecimento do número mínimo e do número máximo de alunos em sala de aula;

II - capacitação permanente dos profissionais da educação;

III - jornada de trabalho que incorpore os momentos diferenciados das atividades docentes;

IV - complexidade de funcionamento;

V - localização e atendimento da clientela;

$\mathrm{VI}$ - busca do aumento do padrão de qualidade do ensino. (BRASIL. 1996b).

Até 1999, não houve nenhum tipo de diferenciação de valores nos custos do Fundef, de 2000 a 2004 estipulou-se um acréscimo de cinco por cento para alunos de $5^{\mathrm{a}}$ a $8^{\mathrm{a}}$ séries e da educação especial, o qual foi elevado ao patamar de sete por centro para esta modalidade em 2005. Em nenhuma das ocasiões os documentos legais que regularam as diferenciações apontaram estudos que respaldassem estes índices, o que remete a atentar-se para a necessidade de gerir contribuições que desvelem as correlações de custo-aluno da educação especial.

O referido Fundo passou a vigorar efetivamente, em âmbito nacional, somente em 1998 e teve forte impacto na divisão de recursos entre os governos estaduais e seus respectivos municípios, bem como entre municípios com diferentes capacidades de arrecadação de impostos dentro de um mesmo Estado. Em suma, o ente federado receberia do Fundo os recursos 
proporcionais ao número de matrículas de ensino fundamental em sua rede de ensino, o que induziu o processo de municipalização supracitado. Concretamente, as redes municipais brasileiras, que respondiam por $37 \%$ dessas matrículas, em 1996, aumentaram suas responsabilidades de modo a atingir o patamar de 60,25\%, em 2006 (BRASIL, 2007).

Esse "movimento municipalizador" foi acompanhado de outras ações aportando novas atribuições educacionais aos gestores das cidades, como os casos da merenda e do transporte escolares, as reformas e manutenções de prédios e equipamentos, o fornecimento de pessoal para escolas estaduais e privadas, entre outras funções. Esse processo tem levado as administrações municipais a criar novas estruturas, ou a ampliar as já existentes, de modo a fazer frente às suas crescentes funções, modificando e tornando mais complexos os respectivos arranjos institucionais da máquina pública.

Em 2007, o Fundef foi substituído pelo Fundo de Manutenção e Desenvolvimento da Educação Básica e de Valorização dos Profissionais da Educação (Fundeb), sendo que este último possui características semelhantes ao seu antecessor, tendo ampliadas, entretanto, suas prerrogativas sobre toda a educação básica. Apesar de não se basear em dados científicos, o diferencial entre os valores destinados aos alunos dos anos iniciais do ensino fundamental e a educação especial passou dos $7 \%$ (Fundef) para $20 \%$, o que significou um aumento expressivo na destinação de recursos financeiros para o setor. Ainda neste sentido foi prevista a implementação, a partir de 2010, da dupla contagem da matrícula dos alunos da educação regular da rede pública que recebem atendimento educacional especializado, significando um novo patamar de investimento na educação especial ${ }^{11}$.

Vislumbram-se, com a implantação do Fundeb, novos rearranjos da organização estatal, sendo importante notar que os dois fundos previram valores financeiros diferenciados a serem destinados às instituições que atendem a educação especial. Estes valores, mais elevados do que os aportados às escolas

11 Decreto $n^{\circ} 6.571$ / 2008 (BRASIL, 2008a). comuns, ainda carecem de estudos quanto ao seu dimensionamento, sendo utilizados, até o momento, índices diferenciados que refletem tanto a disponibilidade financeira dos governos quanto a correlação de forças políticas em disputa pelos parcos recursos.

Em outros termos, os fatores de ponderação estipulados para o Fundeb não estão assentados em dados técnicos que evidenciem as justificativas de suas diferenciações e as decisões sobre esses valores advém essencialmente dos embates políticos entre diferentes grupos.

Por outro lado, estudos indicam que os custos da educação especial são bem maiores do que os aportes oficiais do Fundeb fazem supor. Por exemplo, Farenzena e Machado (2006) apontam que essa modalidade utiliza, no Brasil, em média quatro vezes mais recursos do que os anos iniciais do ensino fundamental, o que indica a necessidade de se aprofundar os estudos nesta área.

\section{A pesquisa e alguns de seus indícios}

No ano de 2004, foi realizada uma pesquisa intitulada "Levantamento do custo-aluno-ano em escolas de educação básica que oferecem condições paraa oferta de umensino de qualidade", concebida e financiada pelo Instituto Nacional de Estudos e Pesquisas Educacionais Anísio Teixeira (Inep) e desenvolvida em rede nacional, por grupos de pesquisa de universidades públicas ou equipes específicas das secretarias estaduais de educação, nos estados de Goiás, Pará, Paraná, Piauí, Rio Grande do Sul, São Paulo e Ceará. O foco do referido estudo foi a definição e análise do custo-aluno-ano em 95 escolas públicas, avaliadas como de qualidade, distribuídas nesses sete estados brasileiros, uma vez que o custo-aluno foi assumido como uma categoria fundamental a ser considerada na definição de políticas públicas relacionadas à criação e à destinação de recursos educacionais.

A listagem de escolas a serem investigadas foi definida a partir de indicação do Inep, selecionadas por meio de um índice que refletia as condições do conjunto de instalações e equipamentos escolares, associadas a novas escolhas, a partir de contribuições locais. 
Foram consideradas basicamente as seguintes variáveis: localização (região, unidade da federação, urbana e rural, capital e não capital); dependência administrativa (federal, estadual e municipal); e tipologia da escola (segundo a oferta de etapas e modalidades de ensino).

É importante destacar que quanto à modalidade de educação especial, o levantamento de dados buscava identificar informações referentes à sua oferta. Foi constatado nas escolas da amostra que a educação especial era oferecida em três modalidades de instituições: escola comum com apoio de sala de recursos, escola comum sem apoio de sala de recursos e escola de ensino regular com classe especial. Contudo, só foram registrados os dados de matrícula geral e por turmas nas escolas de ensino regular com classe especial, o que consequentemente limitou a análise de custo destes casos. Dentre as escolas definidas no estado de São Paulo, somente uma possuía classe especial de atendimento a alunos surdos, o que traduziu a fragilidade dos dados obtidos neste estudo em relação ao custo-aluno-ano que recebe atendimento na modalidade educação especial.

Dada a constatação e divulgação dos resultados da citada pesquisa, assim como de outro estudo que contemplou diversos aspectos relativos à educação especial, mas não o seu financiamento, intitulado "Educação Inclusiva: o desafio de ampliar o atendimento de alunos com qualidade e a formação docente", desenvolvido em parceria pela Feusp, Centro Universitário "Fundação Santo André" (Cufsa) e Secretaria de Educação, Cultura, Esporte e Lazer do município de Diadema (Secel / Diadema), com financiamento da Fundação de Apoio à Pesquisa do Estado de São Paulo (Fapesp), abrangendo o período 2002-2006, um novo grupo de pesquisa foi formado em 2005 contando com a participação de alguns dos integrantes das pesquisas anteriores ${ }^{12}$, a fim de unir esforços para produzir conhecimentos sobre políticas públicas de educação especial, particularmente no que

12 Entre os integrantes da primeira pesquisa citada, faziam parte, além de outros participantes: Juca Gil, Ananda Grinkraut, Andrea de Carvalho Zichia e Luciane Muniz Ribeiro Barbosa. Da segunda pesquisa mencionada fazia parte Rosângela Gavioli Prieto. Estes integrantes também autores do presente artigo. concerne à análise de sua gestão e financiamento em municípios paulistas, pois, como já mencionado, as indicações nos documentos oficiais são para adoção do paradigma da educação inclusiva e foram estruturados, em âmbito nacional, novos mecanismos de financiamento dos sistemas escolares, como o Fundef e o Fundeb, os quais, por sua vez, também contribuíram para a criação de outras configurações institucionais nos municípios.

A parte da pesquisa aqui abordada dedicouse à descrição e análise de diferentes arranjos institucionais de educação especial adotados pelas administrações públicas. A sua finalidade era averiguar como estava efetivado o direito ao atendimento educacional especializado, ou seja, identificar quais eram os recursos e serviços disponibilizados para pessoas com deficiência, transtornos globais do desenvolvimento e altas habilidades / superdotação em municípios paulistas com o fito de caracterizar as redes de ensino e descrever a estrutura e organização de serviços e recursos para atender esse alunado.

Os municípios selecionados ${ }^{13}$ possuíam, em comum, as seguintes características: ofereciam atendimento de educação especial por meio de serviços públicos municipais; esse atendimento abrangia pessoas com deficiência, com transtornos globais do desenvolvimento e, em alguns casos, com altas habilidades/ superdotação; e a intervenção pública ocorria tanto por meio da matrícula desse alunado em classes comuns quanto em serviços especializados (escolas especiais e classes especiais, estas existentes em apenas um dos municípios e apenas para atender surdos).

Além disso, todos os municípios escolhidos eram categorizados pelo Instituto Brasileiro de Geografia e Estatística (IBGE) como sendo de grande porte, ou seja, possuem entre 100 e 900 mil habitantes. Esta característica impossibilita o uso dos resultados obtidos para quaisquer generalizações, pois a ampla maioria dos municípios brasileiros possui menor dimensão do que os abrangidos por esta pesquisa, o que

13 Os nomes dos municípios serão ocultados devido aos compromissos assumidos com as fontes consultadas quanto ao seu anonimato. 
interfere diretamente nas análises empreendidas. No mais, eram municípios localizados nas redondezas da capital do Estado de São Paulo e se, por um lado, ofereciam boas condições de acesso aos pesquisadores, que tinham contatos preexistentes com membros das equipes de gestão, possibilitando com maior facilidade a coleta dos dados da pesquisa, por outro, não se constituíam em bons parâmetros nacionais quanto às condições socioeconômicas locais.

Foram compiladas, caracterizadas e selecionadas as fontes documentais sobre o atendimento de pessoas com necessidades educacionais especiais e sobre financiamento da educação especial nos municípios selecionados. Optou-se por fazer, inicialmente, o piloto dessa investigação em um dos municípios por haver um acúmulo de informações coletadas devido a pesquisas anteriores realizadas por um dos coordenadores deste estudo.

Antes de iniciar a coleta de dados, foram construídos os instrumentos para a obtenção das informações e realizadas reuniões para o seu aprimoramento. Posteriormente, foram feitos contatos com gestores da educação e educação especial, assim como com os responsáveis pelo serviço de atendimento educacional especializado e diversos Conselhos existentes a fim de identificar as ações realizadas pelo município.

Entrevistas foram realizadas junto às pessoas contatadas para coleta de informações complementares e avaliativas da política de educação especial, bem como sobre os trâmites orçamentários. As entrevistas foram gravadas, mediante autorização prévia dos entrevistados e, após a realização de transcrição e síntese das mesmas, foram realizadas leituras para elaboração de categorias de análise.

Para ilustrar o estudo, foram realizados registros fotográficos de equipamentos e materiais utilizados para o atendimento educacional especializado e demais imagens que poderiam contribuir para a realização desta pesquisa.

Alguns dos resultados obtidos apontam para a riqueza de possibilidades a serem exploradas nesse âmbito de investigação. A educação especial constitui-se numa política eminentemente intersetorial, na qual atuam, entre outras, as áreas de saúde, assistência social, transporte e educação. Não obstante o fato de todas as políticas educacionais potencialmente demandarem ações destes setores, o atendimento às pessoas com necessidades educacionais especiais parece catalisar de modo mais incisivo a interveniência de diferentes órgãos e profissionais devido às peculiaridades intrínsecas aos serviços abrangidos. Porém, os diferentes setores da administração pública demonstram baixo poder de interlocução interna a cada esfera governamental, inexistindo um fluxo eficiente de informações e gerando ações nem sempre relacionadas entre si.

Além da marcante presença de múltiplos órgãos das administrações municipais nos trabalhos atinentes aos estudantes com necessidades educacionais especiais, é freqüente a atuação em caráter complementar ao atendimento público de organizações privadas sem fins lucrativos. É notável também a ação residual e frágil da administração pública estadual nos municípios pesquisados. Apesar desta ser responsável, no conjunto do Estado de São Paulo, por grande parcela dos alunos de ensino fundamental e praticamente toda a rede pública de ensino médio, parece haver uma municipalização informal dos serviços devido à omissão do governo estadual na constituição de escolas, contratação de pessoal e definição clara de ações e formas de atendimento constituintes da educação especial.

Notou-se ainda que diversos conselhos municipais tinham por atribuição pensar políticas para as pessoas com necessidades educacionais especiais, no entanto, estes colegiados demonstraram possuir visão ainda reduzida sobre o assunto, restrita a informações esparsas e concentradas em poucos conselheiros. Os conselhos, apesar do compromisso expresso pelos seus componentes entrevistados, apresentaram pouco poder de influenciar as políticas de educação especial e raramente pautaram esta modalidade de ensino em suas reuniões.

A novidade parece ter sido a crescente intervenção do Ministério Público, o qual expressou forte interesse sobre a educação 
especial, atuando de modo a cobrar ações mais enérgicas das administrações municipais no sentido de melhor atender essa modalidade de ensino. As Promotorias da Infância e da Juventude consultadas demonstraram incluir em suas agendas este tema, cumprindo, assim, uma de suas atribuições, interessando-se em dominar o campo dos direitos dessas pessoas e dos deveres do Estado para, inclusive, propor políticas, sendo que nos casos estudados elas contribuíram significativamente para a implantação de novos atendimentos. Estas são constatações relevantes, mas considerase fundamental refletir e estudar mais profundamente acerca dos significados dessas novas intervenções ${ }^{14}$.

14 Cury e Ferreira (2009) apresentam uma instigante abordagem acerca da "judicialização da educação".
$\mathrm{Na}$ perspectiva de continuidade das investigações sobre a gestão da educação especial ressalta-se que as informações públicas sobre o atendimento desta modalidade apresentaram pouca sistematicidade tanto em sua coleta quanto em seu armazenamento e disponibilização, dificultando a caracterização da atuação estatal, por um lado, e tornando ainda mais relevante os trabalhos de pesquisa para que se possam elaborar imagens panorâmicas e detalhadas das políticas deste campo. Destaca-se, por fim, a necessidade de se conhecer melhor os mecanismos de financiamento da educação especial, bem como os custos dos diversos tipos de atendimentos desta modalidade, cuja diversidade intrínseca condena as generalizações e simplificações a dificultarem a compreensão do que ocorre nas administrações públicas e nos serviços privados que orbitam ao redor daquelas.

\section{Referências Bibliográficas}

ALPINO, A. M. S.; EMMEL, M. L. G. Atendimento educacional de alunos com paralisia cerebral no ensino público regular de Londrina. In: MARQUEZINI, M. C. et al. (Orgs.). Inclusão. Londrina: Eduel, 2003. p. 97 -110.

BASSI, M. E.; VIEGAS, L. T. A educação especial no âmbito da política de fundos no financiamento da educação. Reflexão e Ação, v.17, p. 54-87, 2009.

BRASIL. Constituição (1988). Constituição da República Federativa do Brasil, promulgada em 5 de Outubro de 1988. Distrito Federal: Diário Oficial da União, 1988.

BRASIL. Congresso Nacional. Constituição (1988). Emenda Constitucional nº. 14, de 12 de setembro de 1996. Distrito Federal: Diário Oficial da União, 1996.

BRASIL. Congresso Nacional. Lei ñ. 9.394, de 20 de dezembro de 1996. Estabelece as Diretrizes e Bases da Educação Nacional. Distrito Federal: Diário Oficial da União, 1996a.

BRASIL. Congresso Nacional. Lei no. 9.424, de 24 de dezembro de 1996. Dispõe sobre o Fundo de Manutenção e Desenvolvimento do Ensino Fundamental e de Valorização do Magistério. Distrito Federal: Diário Oficial da União, 1996b.

BRASIL. Ministério da Educação e do Desporto. Secretaria de Educação Especial. Educação especial no Brasil: perfil do financiamento e das despesas. Série Institucional, n. 3. Pesquisadores: Candido Alberto Gomes e José Amaral Sobrinho; colaboradores: Dalva Guaraciara Cardoso, et. al. Brasília: MEC/SEESP/UNESCO, 1996c.

BRASIL. Congresso Nacional. Lei nº. 11.494, de 20 de junho de 2007. Regulamenta sobre o Fundo de Manutenção e Desenvolvimento da Educação Básica e Valorização dos Profissionais da Educação - FUNDEB. Distrito Federal: Diário Oficial da União, 2007a.

BRASIL. Conselho Nacional de Educação. Câmara de Educação Básica. Resolução CNE/CEB ño 2, de 11 de setembro de 2001. Diretrizes Nacionais para a Educação Especial na Educação Básica. Distrito Federal: Diário Oficial da União, 2001.

BRASIL. Ministério da Educação. Instituto Nacional de Estatísticas e Pesquisas Educacionais Anísio Teixeira. Sinopse Estatística da Educação Básica: Censo Escolar 2006. Brasília: MEC/INEP, 2007.

BRASIL. Ministério da Educação. Secretaria de Educação Especial. Política Nacional de Educação Especial na perspectiva da educação inclusiva. Brasilia, DF: MEC, 2008.

BRASIL. Decreto nº.571, de 17 de setembro de 2008. Dispõe sobre o atendimento educacional especializado. Braślia, 2008a.

CARVALHO, M. B. W. B. A educação especial na política educacional do Maranhão. In: MARQUUEZINE, M. C.; ALMEIDA, M. A.; TANAKA, E. D. 0. (Orgs.). Educação especial: políticas públicas e concepções sobre deficiência. Londrina: Eduel, 2003, p. 13 - 24. 
CURY, C. R. J.; FERREIRA, L. A. M. A judicialização da educação. Revista CEJ, Ano XIII, n. 45, p. 32 - 45. 2009.

DUARTE, M. M. N. B. Educação especial pública e municipal em Mauá: um resgate histórico. In: DOTTA, R. A.; P., M. T.; DUARTE, M. M. N. B. (Orgs.). Cem anos de educação: das escolas isoladas ao sistema municipal. São Paulo: Imprensa Oficial, v. 1, 2004, p. 121-135.

FARENZENA, N.; MACHADO, M. G. F. 0 custo das escolas públicas municipais: resultados de uma pesquisa e implicações políticas. Revista Brasileira de Política e Administração da Educação, v. 22, p. 277 - 290. 2006.

LAURO, B. B. et al. Construindo uma educação infantil inclusiva. In: MARQUEZZINI, M. C. et al. (Orgs.). Inclusão. Londrina: Eduel, 2003, p. 79 - 88. MATOS, N. D. A política de educação especial no estado de Sergipe (1979-2001). Revista Brasileira de Educaçãa Especial. Marília, v. 13, n. 1, p. $77-94.2007$.

MENDES, E. G. M. Perspectivas para a construção da escola inclusiva no Brasil. In: MARINS, C.; PALHARES, M. S. (Orgs). Educação inclusiva. São Carlos: Edufscar, 2002, p. 61 - 85.

OLIVEIRA, A. A. S.; POKER, R. B. Educação inclusiva e municipalização: a experiência em educação especial de Paraguaçu Paulista. Revista Brasileira de Educação Especial, Marília, v. 8, n. 2, p. 233 - 244. 2002.

PRIETO, R. G. Política educacional do município de São Paulo: estudo sobre o atendimento de alunos com necessidades educativas especiais, no período de 1986 a 1996. 2000. 260f. Tese (Doutorado em Educação) - Faculdade de Educação, Universidade de São Paulo, São Paulo, 2000.

PRIETO, R. G. et. al. Educação inclusiva: 0 desafio de ampliar o atendimento com qualidade e a formação docente. Pesquisa financiada pela Fapesp - linha de políticas públicas. São Paulo: FEUSP/CUFSA, 2006. (Relatório de Pesquisa).

PRIETO, R. G.; SOUSA, S. M. Z. Educação especial no município de São Paulo: acompanhamento da trajetória escolar de alunos no ensino regular. Revista Brasileira de Educação Especial. Marília, v. 12, n. 2, p. 187 -202. 2006.

PRIETO, R. G. Educação especial: o atendimento em salas de recursos na rede municipal de São Paulo. Educação. Revista do Centro de Educação da Universidade Federal de Santa Maria, v. 32, n. 2, p. 261 - 512. 2007. (Dossiê: Educação Inclusiva)

SILVEIRA, L. C. et al. Inclusão em creches da rede municipal de São Carlos. In: MARQUUEZINI, M. C. et al. (Org.). Inclusão. Londrina: Eduel, 2003. p. $121-132$.

SOUSA, S. MI Z. L.; PRIETO, R. G. Atendimento educacional aos portadores de deficiência mental na rede municipal de São Paulo: caracterização e análise das SAPNEs. Revista Brasileira de Educação Especial. Marília, v. 7, n.1, p. 101 - 115. 2001.

VIEGAS, L. T. Financiamento da educação: estudos preliminares sobre a educação especial. In: V Seminário Nacional de Pesquisa em Educação Especial, 2009, São Paulo-SP. Anais... São Paulo: UFRGS/UFES/UFSCar, 2009, cd-rom.

ZANATA, E. M. Avaliação do primeiro ano de implantação de um projeto de inclusão em uma escola de ensino fundamental da rede pública no estado de São Paulo. In: MARQUEZINI, M. C. et al. (Org.). Inclusão. Londrina: Eduel, 2003. p. 89 - 95.

Recebido em fevereiro de 2010

Aprovado em maio de 2010 